\title{
Effects of low-intensity DC magnetic field on the freezing process of aqueous solution and beef
}

\author{
Yiran WANG ${ }^{1}$ (D), Teng XU1 , Gengbin TAN ${ }^{1}$, Hailong $\mathrm{CHEN}^{1}$, Tao $\mathrm{LI}^{1 *}$ and Dongxing $\mathrm{DU}^{1 *}$
}

\begin{abstract}
s
In this paper, experiments were conducted to study the effect of weak magnetic fields on the freezing process of deionized water and physiological normal saline. The results show that different magnetic field strengths have different effects on aqueous solutions. Only a certain strength of the magnetic field will have a positive effect on the freezing process of the aqueous solution, and generally speaking, the effect of the magnetic field on the normal saline is better than that of deionized water. When the magnetic field strength is 150G, the magnetic field has a positive effect on the supercooling degree and the supercooling time of the saline. In the beef freezing experiment, it was found that the magnetic field can not only promote the freezing process of beef but also inhibit the freezing process. Whether a fan is added will also affect the freezing effect of the magnetic field on the beef.The magnetic field strength of $40 \mathrm{G}$ and $50 \mathrm{G}$ has a significant promotion effect on the freezing process of beef, while the magnetic field strength of $100 \mathrm{G} \sim 150 \mathrm{G}$ has a significant inhibitory effect.
\end{abstract}

Keywords: magnetic field intensity; supercooling degree; supercooling time; freezing.

Practical Application: The data in this article are available

\section{Introduction}

Freezing, i.e. holding food in a refrigerated environment with the majority of the water in the food turned into ice, is a major preservation method for foods. Generally speaking, the quality of frozen food is closely related to the freezing process. The rate of freezing and the heat conductivity of food in freezing is critical to minimize tissue damage. The freezing process of food matrices is affected by their dominant constituent which is water. The final quality of the frozen product depends on the phase transition or the crystallization process of changing water into ice. During the freezing process, ice crystallization can result in irreversible damages to tissue structures which in turn degrade the texture and color of the product (Xanthakis et al., 2014). it is important to investigate the ice crystallization process within food products under proper storage conditions. Currently, researchers have also done a lot of research on the effects of other factors (such as ultrasound, electric field, magnetic field, ultra-high pressure, etc.) on the freezing process, with the consideration of energysaving and/or quality improvement. Magnetic field auxiliary quick freezing technology, as athermal technology-aided food freezing process has been a research hotspot in recent years.

The ice crystallization process can be divided into three subsequent stages, i.e., cooling the liquid-state product to its freezing point (pre-cooling or chilling stage), removing the latent heat of crystallization during the phase transition (phase transition stage), and cooling the solid-state product to the final storage temperature (tempering stage), as shown in Figure 1. Previous research efforts have been made to shorten the freezing period, increase the freezing rate, and maintain temperature stability during freeze-storage based on the temperature profile during the freezing process. A great number of papers on the effect of magnetic field on the physical and chemical properties of water, aqueous solutions, and salt crystallization in MF have been published during the last years (Wowk, 2012; Li \& Sun, 2002; Kiani \& Sun, 2011). Diamagnetic properties of water molecules under the magnetic field were intensively studied, and theoretical and experimental results showed that the magnetic field can make impacts on water structures (Aleksandrov et al., 2000; Woo \& Mujumdar, 2010; Iwasaka et al., 2011). Zhou et al. (2012) investigated the supercooling and crystallization of water under DC magnetic fields with different intensities, and they found that the DC magnetic field can reduce the lowest unfrozen temperature and increase supercooling. The time that water remains supercooled increases with the increase of intensity of the DC magnetic field. The crystallization speed also increases obviously. Pang \& Deng (2008) analyzed the infrared adsorption spectrum and Raman spectrum of magnetized water and they found that static magnetic field causes changes only in the distribution and polarization of the molecules but not in the constitution of water. Holysz et al. (2007) investigated the influence of a static magnetic field $(B=15 \mathrm{mT})$ on water and electrolyte solutions $\left(20 \pm 1{ }^{\circ} \mathrm{C}\right)$ and concluded that a magnetic field influences conductivity and evaporation rate of water due to change the hydrating water structure around the ions. Szcześ et al. (2010) found that the MF decreases the water conductivity and increases the amount of evaporated water. Mok et al. (2015) reported that the effect of MF was observed not only in the ice crystal shape but also in the phase transition time in the freezing process of normal saline ( $0.9 \%$ mass concentration $\mathrm{NaCl}$ solution). They 
mentioned that the phase change time is prolonged when an attractive MF is applied but reduced in repulsive MF. Due to the diamagnetic properties of water and ionic interactions, $\mathrm{Na}+$ and $\mathrm{Cl}$ - ions could cause the hydrogen bonding to be ruptured under the magnetic fields (Chang \&Weng, 2008). Both of the van der Waals bonding between water molecules and the interaction between ions and water molecules were influenced by the attractive or repulsive static magnetic field. (Simon et al., 2001; Ueno \& Iwasaka, 1994; Guo et al., 2011; Chang \& Weng, 2006; Toledo et al., 2008).

However, other researchers have different views on the impact of the magnetic field on the freezing process. Some authors have compared the quality of several foods frozen in both commercial electromagnetic freezers and conventional devices (Choi et al., 2015; Erikson et al., 2016; Kim et al., 2013; Yamamoto et al., 2005). Unfortunately, the few existing studies provide little or no information about the characteristics of the magnetic fields applied. Suzuki et al. (Suzuki et al., 2009) applied a weak magnetic field of $0.5 \mathrm{mT}$ to the biological tissue during the freezing process and found that the temperature field did not change significantly. Wowk (2012) considered that the evidence that magnetic fields can respectively promote or inhibit the formation of ice is less persuasive. James et al. (2015) compared the freezing curves of garlic bulbs frozen with (0.1$0.4 \mathrm{mT}$ ) and without oscillating magnetic fields application in a Cells Alive System freezer. They did not find any effect of the oscillating magnetic fields on the supercooling reached in the samples or on the freezing kinetics. Otero et al. (2017) froze

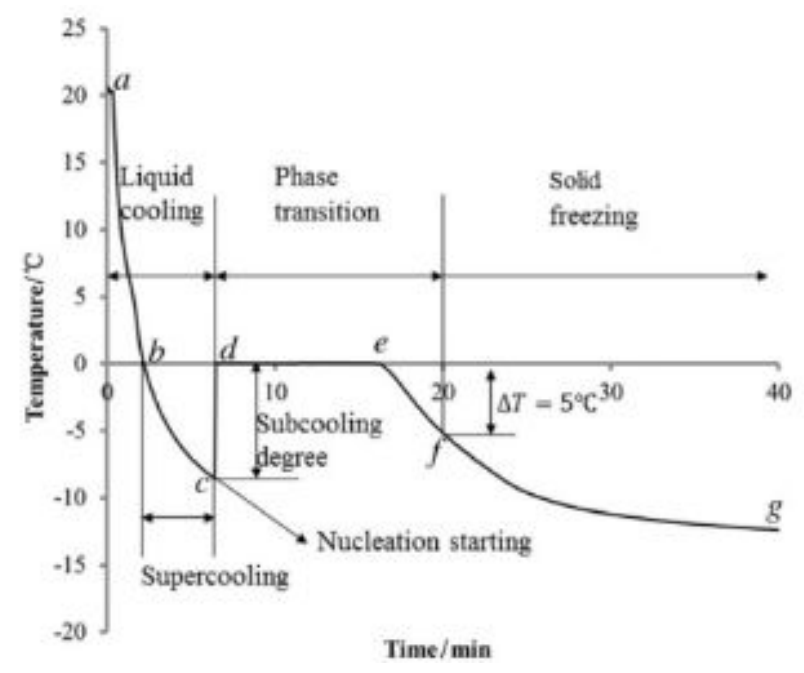

Figure 1. The typical freezing curve of water. crab sticks in a commercial electromagnetic freezer, both with $(<2 \mathrm{mT}, 6-59 \mathrm{~Hz})$ and without OMF application, but they did not find any effect of the oscillating magnetic fields on the drip loss, water-holding capacity, toughness, and whiteness of the crab sticks frozen in the electromagnetic device. Moreover, no advantage of electromagnetic freezing over air-blast freezing was detected at the conditions tested.

Therefore, more research is needed to prove that magnetic fields can affect ice formation during cryopreservation through non-thermal mechanisms. Deionized water and $0.9 \% \mathrm{NaCl}$ solution (considered as a physiological and biological solution) have been used in this study to explore the effect of a DC magnetic field on the aqueous solution by comparing the two solutions. The influence of the magnetic field on the freezing process of brine can guide the freezing and cryopreservation of meat products. On this basis, this article uses beef as a representative of meat to explore the influence of different magnetic field strengths on the freezing process.

\section{Experimental device and method}

\subsection{Laboratory apparatus}

The liquid samples tested are deionized water and normal saline. Deionized water is pure water after removing impurities in the form of ions. All solutions were stored in polyethylene flasks to avoid any contamination coming from glass surfaces. Before each experiment, $100 \mathrm{~mL}$ of a freshly prepared sample (samples were not reused) was located in a $150 \mathrm{~mL}$ beaker and tempered in a thermostatic bath for, at least, $60 \mathrm{~min}$ to achieve a uniform temperature of $20 \pm 0.5^{\circ} \mathrm{C}$. The instruments used in the experiment are listed in Table 1.

\subsection{Magnetic device}

The magnetic field generating system consisted of a pair of Helmholtz coils, DC power supply 0-40V, amperemeter, voltmeter, and gauss-meter. The Helmholtz coil consisted of a pair of DC circular coils separated by a distance equivalent to the radius $(150 \mathrm{~mm})$ of the circular loops. Each coil contained 300 turns of copper wire with a cross-sectional area of 2.5 square millimeters. It produced a homogeneous magnetic field with 0 frequency between the two circular coils as shown in Figure2. In the numerical simulation, coil wire conductivity is $6 \mathrm{e} 7 \mathrm{~S} / \mathrm{m}$, coil wire cross-section area is $1 \mathrm{e}-6 \mathrm{~m} 2$, and coil voltage is $13.25 \mathrm{~V}$, the Helmholtz coil produces a nearly uniform magnetic field of $50 \mathrm{G}(10 \mathrm{G}=1 \mathrm{mT})$. The magnetic field flux density $\mathrm{B}(\mathrm{B}=50 \mathrm{G}$ $100 \mathrm{G}, 150 \mathrm{G}$ ) was adjusted by changing the voltage or current of the coils. The target group was placed at the central axis of the

Table 1. Laboratory apparatus.

\begin{tabular}{ccc}
\hline DC power supply & WYK-10020, Eastern Group East Group Co., Ltd & $0 \sim 40 \mathrm{~V}, 0 \sim 10 \mathrm{~A}$ \\
\hline Handheld Digital Tesla Meter & TD8620, Chan Gha Tianheng Measurement and & accuracy is $\pm 2 \%$ when the test range is \\
& Control Technology Co., Ltd & $0 \sim 1000 \mathrm{mT}$ \\
Optical fiber temperature online monitoring & FAS-F, Beijing Feibote Optoelectronics & Temperature range $-50^{\circ} \mathrm{C} \sim 200^{\circ} \mathrm{C}, \pm 0.5^{\circ} \mathrm{C}$ \\
device and optical fiber temperature sensor & Technology Co., Ltd. & $10^{\circ} \mathrm{C} \sim-20^{\circ} \mathrm{C}$ \\
direct cooling refrigerator & BCD-160TMPQ, Haier Co., Ltd & $10^{\circ} \mathrm{C} \sim-40^{\circ} \mathrm{C}$ \\
Air-cooled refrigerator & BC/BD-280WEGU1 & \\
\hline
\end{tabular}



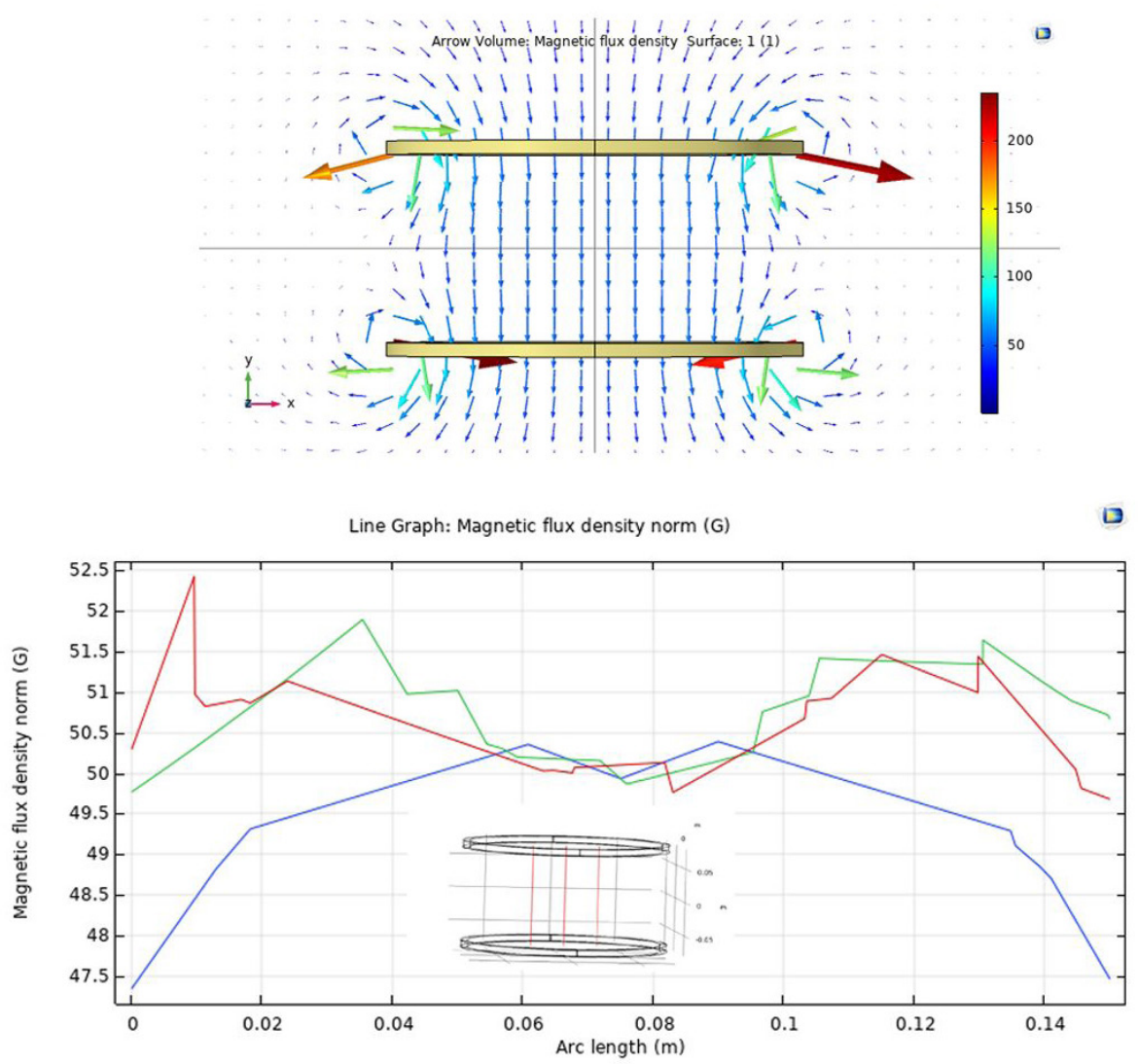

Figure 2. Distribution of magnetic lines of Helmholtz coil.

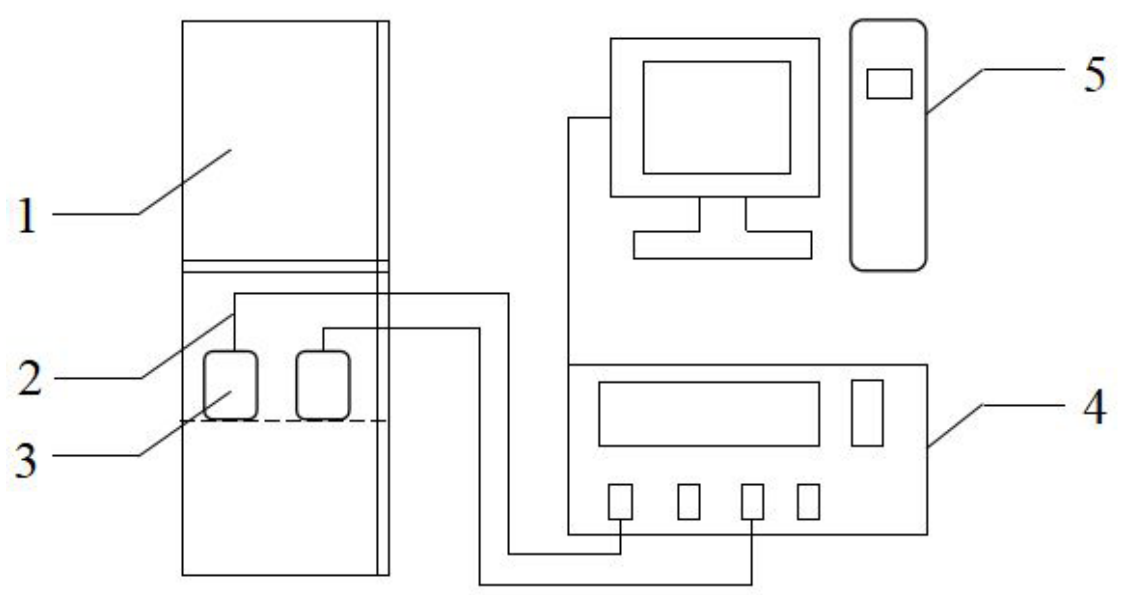

Figure 3. The experimental device diagram of aqueous solution freezing; 1 - Refrigerator, 2 - Fiber optic thermometer, $3-$ Sample container, 4 -Data acquisition instrument, 5 - Computer.

coils. The Control group was placed in absence of coils. Both groups were in a room temperature environment.

The experimental system of water and the aqueous solution is shown in Figure 3, and the experimental device of beef freezing is shown in Figure 4. The optical fiber temperature sensor FAS-F located in the center of the sample can measure the temperature of the sample, and the corresponding data is collected through the data acquisition system (Agilent 34970A) And transfer to the computer.

\subsection{Freezing experiments}

In the freezing experiment of deionized water and normal saline, before each experiment, put $100 \mathrm{~mL}$ of freshly prepared samples (samples that are not reused) into a $150 \mathrm{~mL}$ beaker and 
temper in a constant temperature bath for at least 60 minutes. To achieve a uniform temperature of $20 \pm 0.5^{\circ} \mathrm{C}$. The two groups were taken out of the water bath at $20 \pm 0.5^{\circ} \mathrm{C}$, and then the target group was placed in a magnetic field for 2 hours. The control group was not treated. After two hours, both samples were placed in a direct-cooling refrigerator (BCD-160TMPQ, Haier, freezing capacity $1.5 \mathrm{~kg} / 12 \mathrm{~h}$ ) at $-18 \pm 0.2{ }^{\circ} \mathrm{C}$ for freezing experiments, and the freezing process of the two samples was recorded. Each experiment is treated with a magnetic field and non-magnetic field, that is, each experiment has an experimental group and a control group. Before the experiment, the cooling curve of different positions in the freezer layer of the refrigerator was measured by the optical fiber temperature sensing device, and two positions with the smallest temperature difference were found, as shown in Figure 5.

In the beef freezing experiment, fresh beef tenderloin was cut into blocks of $5 \mathrm{~cm} \times 5 \mathrm{~cm} \times 2 \mathrm{~cm}$ and then divided into several groups. The weight of each group was $40 \mathrm{~g}$, and the difference

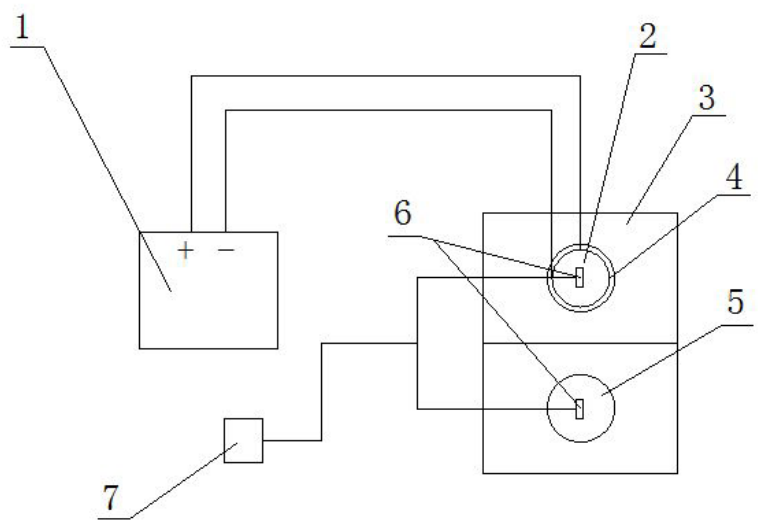

Figure 4. Beef freezing experimental device diagram; 1-DC power supply, 2-Magnetic field, 3-Air-cooled refrigerator, 4-Helmholtz coil, 5-Control area, 6-Fiber optic thermometer, 7-data collection system.

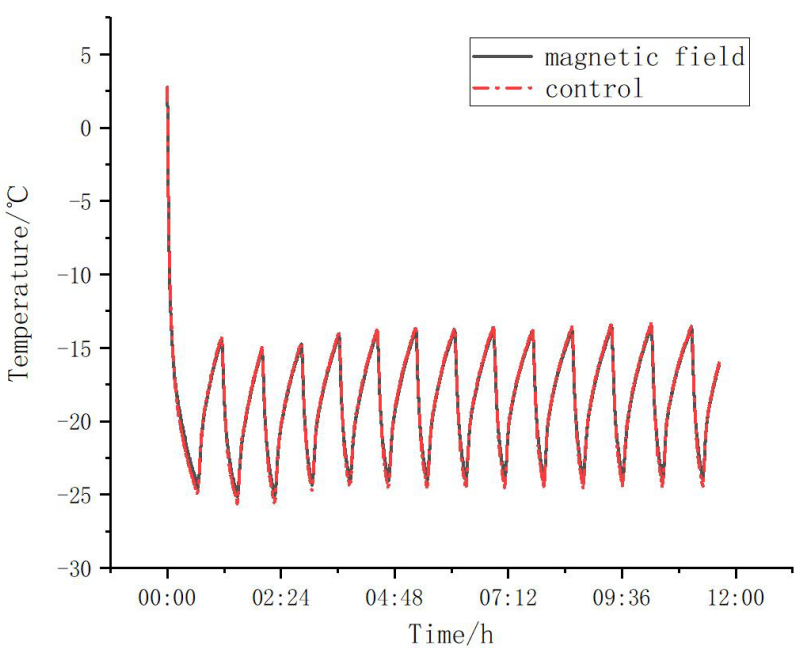

Figure 5. Temperature curve of two parts of the refrigerator. in quality was no more than $1 \%$. By adjusting the voltage to set different magnetic fields to process the beef during freezing, set the temperature of the refrigerator freezer (BC/BD-280WEGU1) at $-30^{\circ} \mathrm{C}$ or lower to reduce the beef core temperature to $-18^{\circ} \mathrm{C}$, Study the difference of its freezing curve; because the energized coil will generate heat, put the magnetic field auxiliary device into the refrigerator freezer before the experiment, and measure the temperature change in the refrigerator, and select the position closest to the temperature of the magnetic field as a control Group area. The four optical fiber temperature measuring devices are distributed as follows in the freezer, where No. 1 is the magnetic field area, and 2\#, 3\#, and 4\# are the candidate areas of the reference group, as shown in the Figure 6. By comparing the temperature change curves, it is found that the position closest to the 1 \# curve under the three magnetic field strengths is always the $3 \#$ area, so the control group is placed in the $3 \#$ temperature measurement area for the experiment.

\section{Results and discussion}

\subsection{Results \& discussion of deionized water}

Figure 7 shows the freezing curves of deionized water under different magnetic field strength conditions. Table 2 shows the supercooling degree and supercooling time of deionized water under different magnetic field strengths. The supercooling degree is an indispensable thermodynamic condition in crystal nucleation, and it is also closely related to the growth process of crystal nuclei. Larger, the longer the corresponding supercooling time. The longer the time in the supercooled state, the better the temperature uniformity, and the more adequate the heat exchange.

According to the experimental data, the freezing point temperature of deionized water is not affected by the magnetic field. Under the action of $50 \mathrm{G}$ magnetic field strength, the experimental group started to crystallize earlier than the control group, and

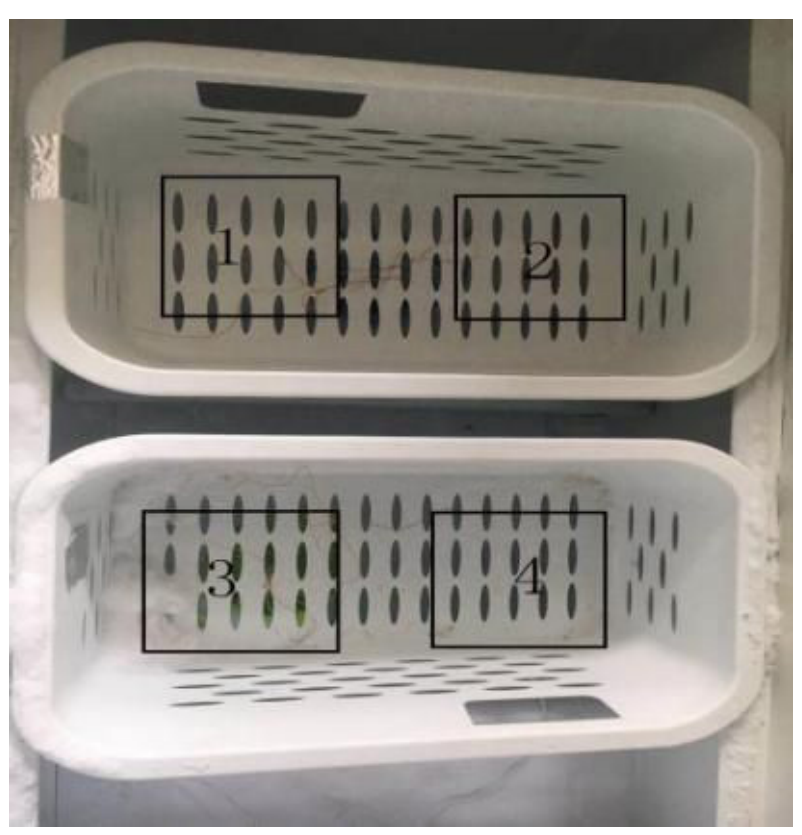

Figure 6. Temperature measuring device layout. 

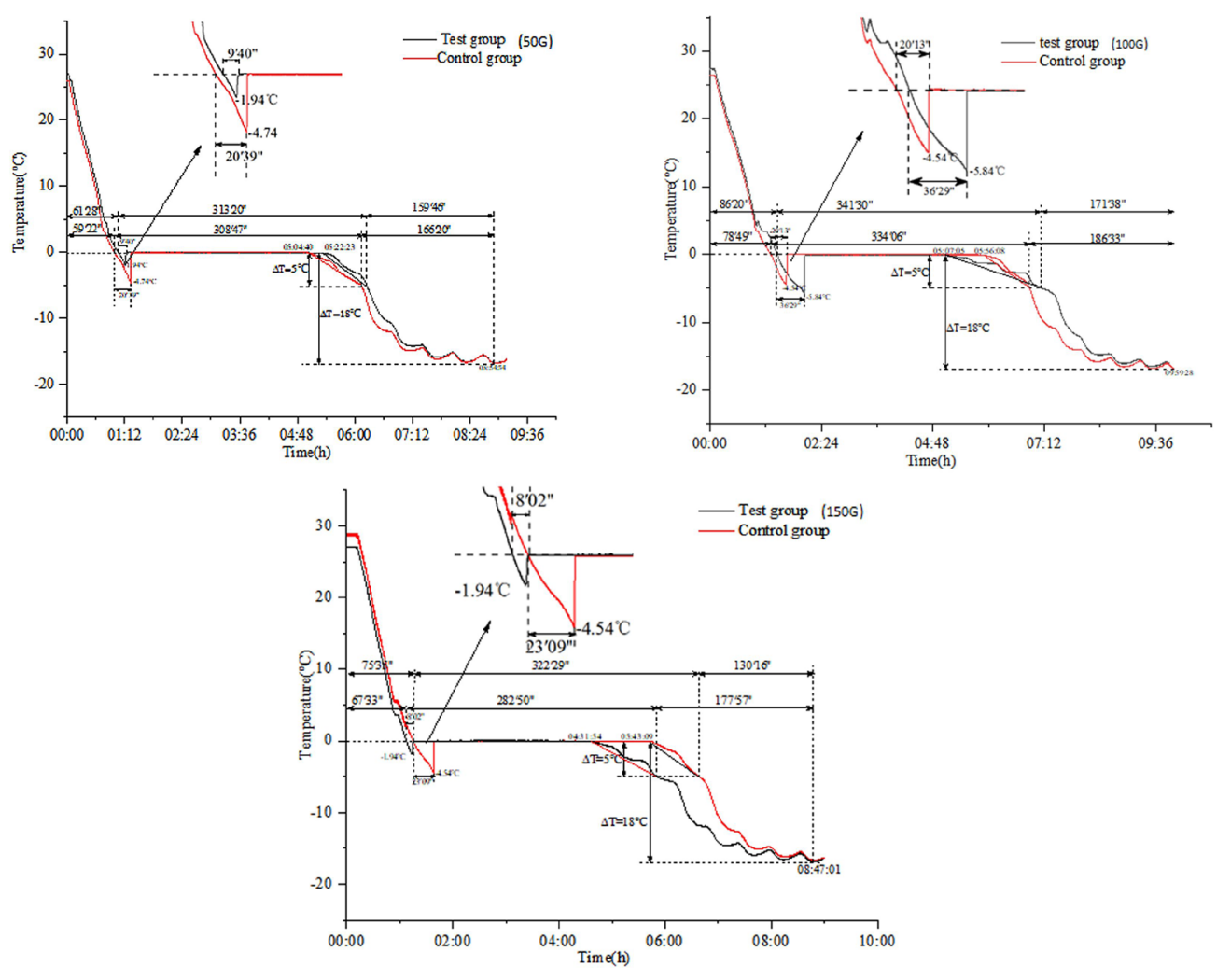

Figure 7. Deionized water freezing curves (50-150G).

Table 2. The supercooling degree and supercooling time of deionized water under different magnetic field intensity.

\begin{tabular}{|c|c|c|c|c|c|c|c|c|c|}
\hline & $\begin{array}{l}\text { DC magnetic } \\
\text { field } \\
\text { intensity /G }\end{array}$ & $\begin{array}{c}\text { Possible } \\
\text { lowest } \\
\text { unfrozen } \\
\text { temperature } \\
{ }^{\circ} \mathrm{C} \\
\end{array}$ & $\begin{array}{c}\text { Possible } \\
\text { lowest } \\
\text { unfrozen } \\
\text { temperature } \\
\quad /{ }^{\circ} \mathrm{C} \\
\end{array}$ & $\begin{array}{l}\text { Freezing } \\
\text { point } /{ }^{\circ} \mathrm{C}\end{array}$ & $\begin{array}{l}\text { Freezing } \\
\text { point }{ }^{*} /{ }^{\circ} \mathrm{C}\end{array}$ & $\begin{array}{c}\text { Super- } \\
\text { cooling } /{ }^{\circ} \mathrm{C}\end{array}$ & $\begin{array}{c}\text { Super- } \\
\text { cooling }{ }^{*} /{ }^{\circ} \mathrm{C}\end{array}$ & $\begin{array}{c}\text { Super- } \\
\text { cooling time }\end{array}$ & $\begin{array}{l}\text { Super- } \\
\text { cooling } \\
\text { time }^{\star}\end{array}$ \\
\hline \multirow{3}{*}{$\begin{array}{l}\text { Deionized } \\
\text { water }\end{array}$} & 50 & -1.94 & -4.74 & 0 & 0 & 1.94 & 4.74 & 9'40" & $20 ' 39 "$ \\
\hline & 100 & -5.84 & -4.54 & 0 & 0 & 5.84 & 4.54 & $36^{\prime} 29^{\prime \prime}$ & $20 ' 13$ " \\
\hline & 150 & -1.94 & -4.54 & 0 & 0 & 1.94 & 4.54 & 8'02" & $23^{\prime} 09^{\prime \prime}$ \\
\hline
\end{tabular}

Note: The upper right of the letter with * indicates the control group data, and the rest are the experimental group data.

the degree of supercooling of the experimental group was lower than that of the control group. When the magnetic field strength is increased to $100 \mathrm{G}$, the magnetic field reduces the minimum non-crystallization temperature of deionized water and prolongs the time for the experimental group to start crystallization. Compared with the control group, the supercooling degree of the experimental group is increased by $1.3^{\circ} \mathrm{C}$, which makes The cold time is also extended. However, under the action of $150 \mathrm{G}$ magnetic field strength, the experimental group started to crystallize earlier than the control group. The degree of supercooling of the experimental group was lower than that of the control group, and the supercooling time was also greatly shortened.

\subsection{Results and discussion of normal saline}

Figure 8 shows the freezing curves of normal saline under different magnetic field strength conditions. Table 3 shows the supercooling degree and supercooling time of normal saline under different magnetic field strengths. It can be seen from Table 2 that the freezing point of normal saline is not affected by the magnetic field, and the freezing point is $0.54{ }^{\circ} \mathrm{C}$ lower than $0^{\circ} \mathrm{C}$, which is consistent with the data in the relevant data (Chen et al. 2008). When the magnetic field intensity is 50G, the supercooling degree of the experimental group is $4.4^{\circ} \mathrm{C}$, which is not much different from the supercooling degree of the control group. From the freezing curve under $50 \mathrm{G}$ magnetic field intensity, it can be seen that the experimental group and the control group start to crystallize at almost the same time, and the freezing curve of the whole freezing process is about the same. When the magnetic field strength increased to $100 \mathrm{G}$, the experimental group began to crystallize later than the control group, and the supercooling degree of the experimental group increased by $1.3^{\circ} \mathrm{C}$ compared with the control group, and the supercooling time was also prolonged. When the magnetic 

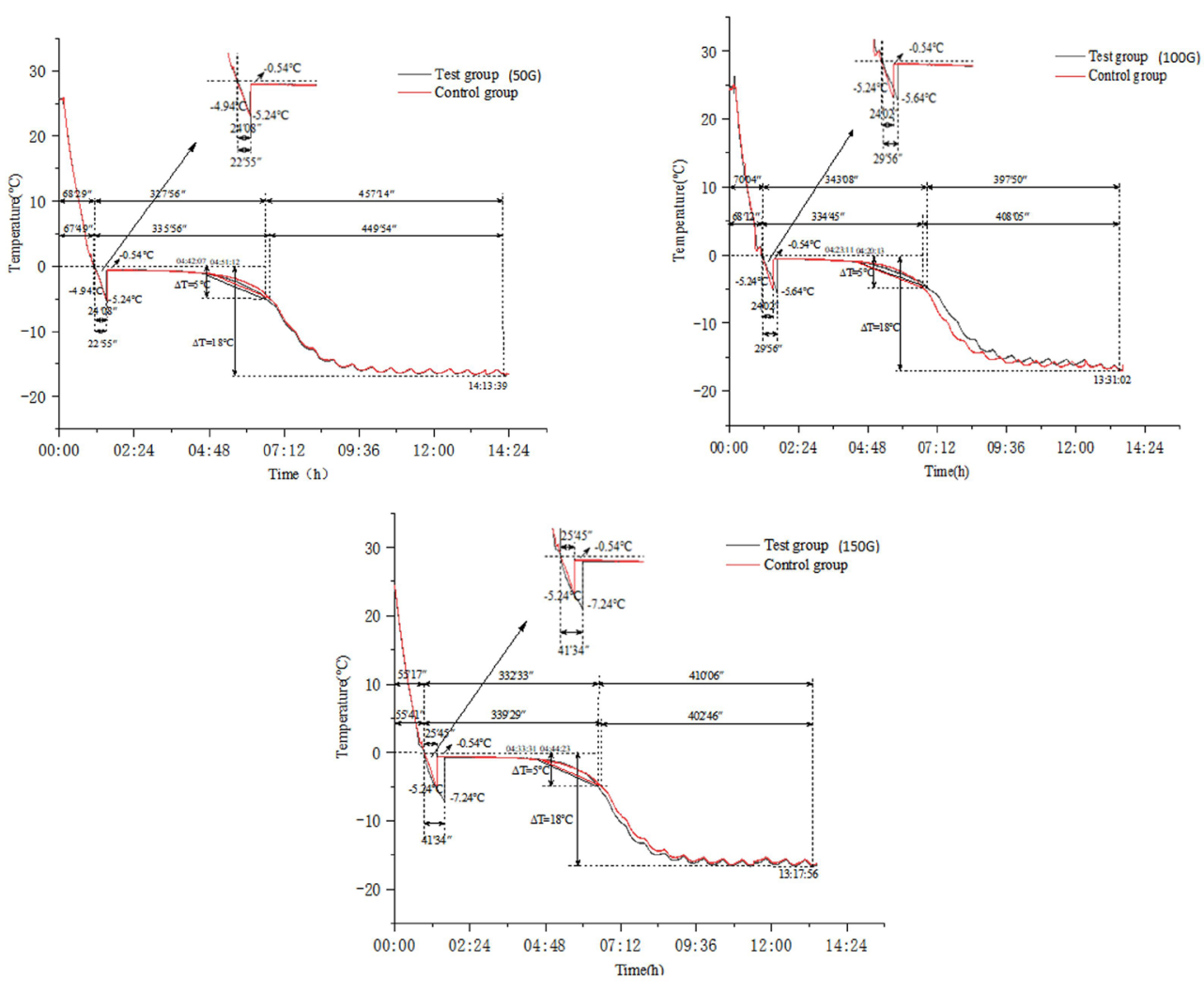

Figure 8. Normal saline freezing curve (50-150G).

Table 3. The supercooling degree and supercooling time of normal saline under different magnetic field conditions.

\begin{tabular}{|c|c|c|c|c|c|c|c|c|c|}
\hline & $\begin{array}{l}\text { DC magnetic } \\
\text { field } \\
\text { intensity /G }\end{array}$ & $\begin{array}{c}\text { Possible } \\
\text { lowest } \\
\text { unfrozen } \\
\text { temperature } \\
/{ }^{\circ} \mathrm{C}\end{array}$ & $\begin{array}{c}\text { Possible } \\
\text { lowest } \\
\text { unfrozen } \\
\text { temperature } \\
/^{\circ} \mathrm{C}\end{array}$ & $\begin{array}{l}\text { Freezing } \\
\text { point } /{ }^{\circ} \mathrm{C}\end{array}$ & $\begin{array}{l}\text { Freezing } \\
\text { point }{ }^{*} /{ }^{\circ} \mathrm{C}\end{array}$ & $\begin{array}{c}\text { Super- } \\
\text { cooling } /{ }^{\circ} \mathrm{C}\end{array}$ & $\begin{array}{c}\text { Super- } \\
\text { cooling }{ }^{*} /{ }^{\circ} \mathrm{C}\end{array}$ & $\begin{array}{c}\text { Super- } \\
\text { cooling time }\end{array}$ & $\begin{array}{l}\text { Super- } \\
\text { cooling } \\
\text { time }^{*}\end{array}$ \\
\hline \multirow{3}{*}{$\begin{array}{l}\text { Normal } \\
\text { saline }\end{array}$} & 50 & -4.94 & -5.24 & -0.54 & -0.54 & 4.4 & 4.7 & $22^{\prime} 55^{\prime \prime}$ & $24^{\prime} 08^{\prime \prime}$ \\
\hline & 100 & -5.64 & -5.24 & -0.54 & -0.54 & 5.1 & 4.7 & $29^{\prime} 56^{\prime \prime}$ & $24^{\prime} 02^{\prime \prime}$ \\
\hline & 150 & -7.24 & -5.24 & -0.54 & -0.54 & 6.7 & 4.7 & $41^{\prime} 34$ "' & $25^{\prime} 45^{\prime \prime}$ \\
\hline
\end{tabular}

Note: The upper right of the letter with * indicates the control group data, and the rest are the experimental group data.

field strength continues to increase to $150 \mathrm{G}$, the time for the normal saline to cool to crystallization is longer than that of the control group. The magnetic field reduces the minimum non-crystallization temperature of the experimental group, which causes the supercooling degree of the experimental group to increase by $2{ }^{\circ} \mathrm{C}$ compared with the control group., The supercooling time is also extended.

\subsection{Results and discussion of beef freezing process}

The influence of magnetic fields on beef freezing process under certain wind speed

Although it is tested that the closest position to the magnetic field area is always the $3 \#$ area, to further reduce the influence of the internal temperature imbalance of the freezer caused by the magnetic field heating, we performed forced ventilation on the magnetic field treatment group and the control group area, choosing between No.1 and Place a small fan under the No.3 area and blow upward from the bottom to make the internal temperature of the freezer more uniform. The experimental results are as follows:

Figure 9 is the freezing curve of beef under different magnetic field strength conditions under a certain wind speed. It can be seen from the Figure that the magnetic field can indeed affect the freezing curve of beef. When the beef drops from normal temperature to $0{ }^{\circ} \mathrm{C}$, the temperature is basically the same, so the two stages of phase change and freezing are mainly considered. The $50 \mathrm{G}$ magnetic field has an obvious promotion effect on the freezing process of beef. The freezing process of beef under the magnetic field strength of $100 \mathrm{G}$ basically does not affect it. When the magnetic field strength increases to $150 \mathrm{G}$, the magnetic field inhibits the freezing process of beef. 


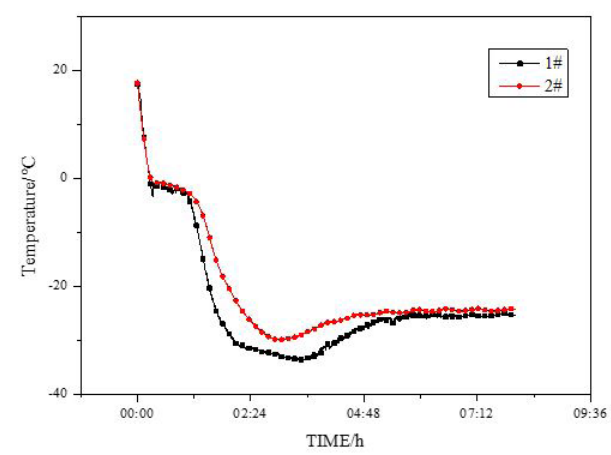

(a) Beef freezing curve (50G)

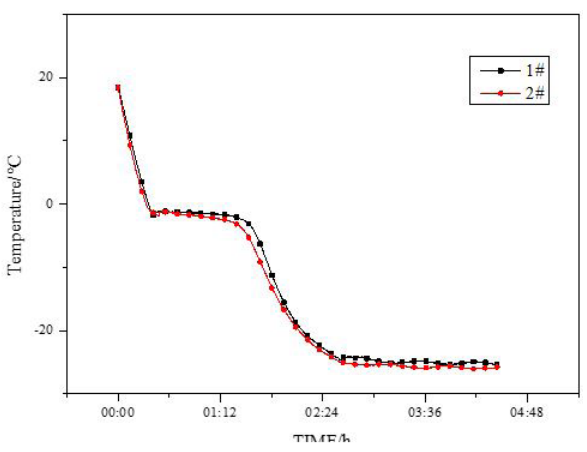

(b) Beef freezing curve (100G)

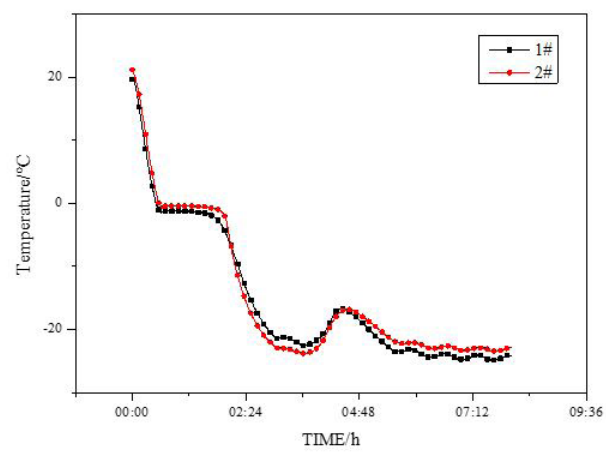

(c) Beef freezing curve (150G)

Figure 9. Freezing curves of beef under different magnetic field intensities at a certain wind speed.

Table 4. The freezing time of beef under different magnetic field intensities at a certain wind speed.

\begin{tabular}{|c|c|c|c|c|c|c|}
\hline \multirow{3}{*}{$\begin{array}{l}\text { Magnetic field } \\
\text { strength/G }\end{array}$} & \multicolumn{6}{|c|}{ time/min } \\
\hline & \multicolumn{2}{|c|}{$0 \sim-5^{\circ} \mathrm{C}$} & \multicolumn{2}{|c|}{$-5^{\circ} \mathrm{C} \sim-18^{\circ} \mathrm{C}$} & \multicolumn{2}{|c|}{$0^{\circ} \mathrm{C} \sim-18{ }^{\circ} \mathrm{C}$} \\
\hline & control group & experimental group & control group & experimental group & control group & experimental group \\
\hline 50 & 60 & 53 & 30 & 19 & 90 & 72 \\
\hline 100 & 71 & 75 & 29 & 26 & 100 & 101 \\
\hline 150 & 88 & 89 & 30 & 42 & 118 & 131 \\
\hline
\end{tabular}

Table 4 shows the freezing time of beef under different magnetic field strengths and different stages under a certain wind speed. Under the action of a 50G magnetic field, the phase transition time and freezing time of the experimental group were shorter than those of the control group, and the total freezing time from $0{ }^{\circ} \mathrm{C}$ to $-18{ }^{\circ} \mathrm{C}$ was the least and most obvious. The phase transition time of the experimental group at $100 \mathrm{G}$ magnetic field strength is slightly longer than that of the control group, and the freezing area time is slightly shorter than that of the control group, so the overall freezing time of the experimental group and the control group are almost the same. With a magnetic field strength of $150 \mathrm{G}$, the phase transition time of the experimental group is almost the same as that of the control group, but the freezing area time is longer than that of the control group.
The influence of magnetic fields on beef freezing process under zero wind speed

To eliminate the influence of forced convective heat transfer on the beef freezing process, the influence of 40G-100G magnetic field strength on the beef freezing process when there is no convective heat transfer in the freezer was tested again.

Figure 10 shows the freezing curves of beef under different magnetic field strengths under zero wind speed. It can be seen from the Figure that the magnetic field strength of $40 \mathrm{G}$ and $50 \mathrm{G}$ accelerates the freezing process of beef, while the magnetic field strength of $65 \mathrm{G}$ has almost no effect on the freezing process of beef. When the magnetic field strength increases to $90 \mathrm{G}$ and $100 \mathrm{G}$, the magnetic field has a significant effect on the freezing process of beef. The inhibitory effect. 


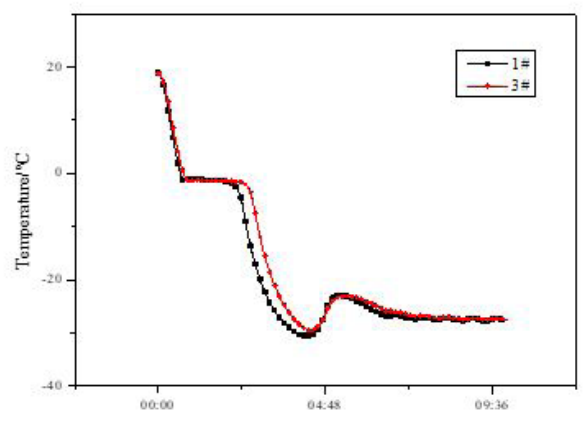

(a) Beef freezing curve $(40 \mathrm{G})$

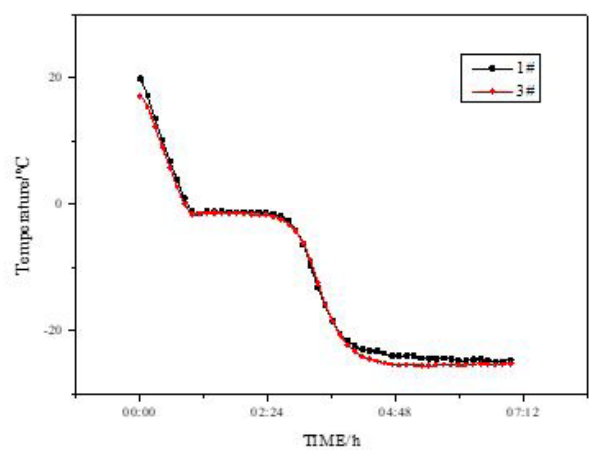

(c) Beef freezing curve(65G)

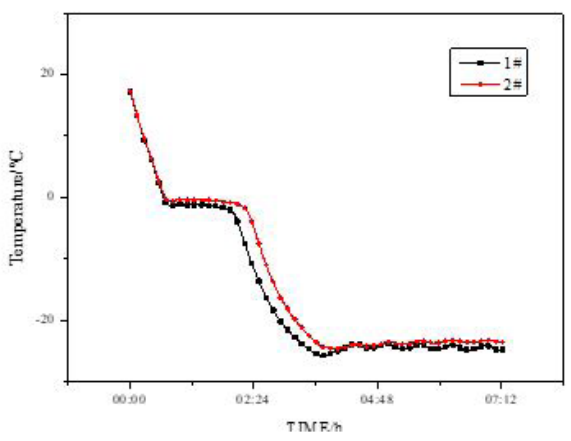

(b) Beef freezing curve $(50 \mathrm{G})$

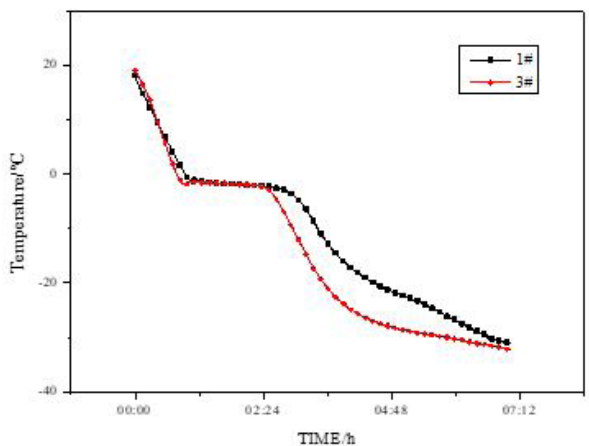

(d) Beef freezing curve $(90 \mathrm{G})$

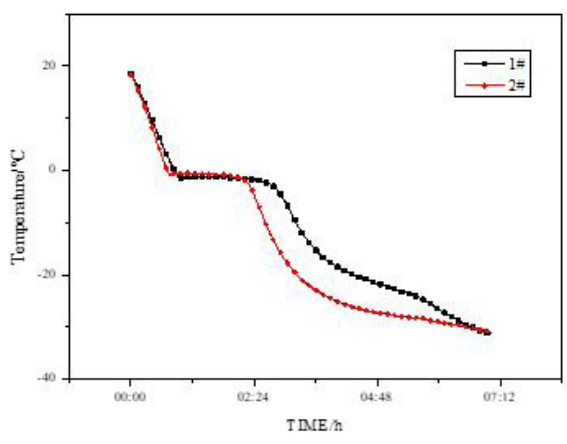

(e) Beef freezing curve(100G)

Figure 10. Freezing curves of beef at zero wind speed under different magnetic field intensities.

Table 5 shows the freezing time of beef under different magnetic field strengths and different stages under zero wind speed. Under the action of $40 \mathrm{G}$ and $50 \mathrm{G}$ magnetic fields, the phase transition time of the experimental group was shorter than that of the control group, and the total freezing time from $0^{\circ} \mathrm{C}$ to $-18^{\circ} \mathrm{C}$ was also shorter than that of the control group. The phase transition zone time and freezing zone time of the experimental group at $65 \mathrm{G}$ magnetic field strength are almost the same as the control group. The phase transition time and freezing time of the $65 \mathrm{G}$ magnetic field strength of the experimental group were slightly longer than those of the control group, and the overall freezing time of the experimental group and the control group was almost the same. When the magnetic field strength increased to $90 \mathrm{G}$ and $100 \mathrm{G}$, the phase change area time and freezing area time of the experimental group were both longer than the control group, making the total freezing time longer than the control group.

\subsection{Summary and comparative analysis of experimental results}

Observing the data in Table 6, the following conclusions are drawn through the comparison of experimental data:

The effect of the magnetic field on the two aqueous solutions is different, and the effect of different magnetic field strengths is also different. Under the magnetic field strength of 100G, the magnetic field reduces the minimum non-crystallization temperature of deionized water, increases the degree of supercooling, and extends 
Table 5. Freezing time of beef under different magnetic field intensities at zero wind speed.

\begin{tabular}{|c|c|c|c|c|c|c|}
\hline \multirow{3}{*}{$\begin{array}{l}\text { Magnetic field } \\
\text { strength/G }\end{array}$} & \multicolumn{6}{|c|}{ time/min } \\
\hline & \multicolumn{2}{|c|}{$0 \sim-5^{\circ} \mathrm{C}$} & \multicolumn{2}{|c|}{$-5^{\circ} \mathrm{C} \sim-18^{\circ} \mathrm{C}$} & \multicolumn{2}{|c|}{$0^{\circ} \mathrm{C} \sim-18^{\circ} \mathrm{C}$} \\
\hline & control group & experimental group & control group & experimental group & control group & experimental group \\
\hline 40 & 118 & 105 & 28 & 26 & 146 & 131 \\
\hline 50 & 103 & 88 & 37 & 37 & 140 & 125 \\
\hline 65 & 125 & 128 & 35 & 36 & 160 & 164 \\
\hline 90 & 113 & 128 & 43 & 64 & 156 & 192 \\
\hline 100 & 102 & 125 & 39 & 59 & 141 & 184 \\
\hline
\end{tabular}

Table 6. Summary table of the influence of magnetic field on the freezing process of two aqueous solutions.

\begin{tabular}{|c|c|c|c|}
\hline Solution category & DC magnetic field intensity /G & Subcooling degree change range $/{ }^{\circ} \mathrm{C}$ & Change range of supercooling time $/ \%$ \\
\hline \multirow[t]{3}{*}{ Deionized water } & 50 & -2.8 & $-113.60 \%$ \\
\hline & 100 & 1.3 & $80.46 \%$ \\
\hline & 150 & -2.6 & $-188.17 \%$ \\
\hline \multirow[t]{3}{*}{ Normal saline } & 50 & -0.3 & $-5.30 \%$ \\
\hline & 100 & 0.4 & $2.15 \%$ \\
\hline & 150 & 2 & $38.05 \%$ \\
\hline
\end{tabular}

Note: All data are based on the control group.

Table 7. Summary of the extension of freezing time of beef at a certain wind speed.

\begin{tabular}{cccr}
\hline \multirow{2}{*}{ DC magnetic field intensity /G } & \multicolumn{2}{c}{ The time extension of the experimental group compared to the control group/\% } \\
\cline { 2 - 4 } & $0 \sim-5{ }^{\circ} \mathrm{C}$ & $-5{ }^{\circ} \mathrm{C} \sim-18{ }^{\circ} \mathrm{C}$ & $0{ }^{\circ} \mathrm{C} \sim-18{ }^{\circ} \mathrm{C}$ \\
\hline 50 & $-11.7 \%$ & $-36.7 \%$ & $-20.0 \%$ \\
100 & $5.6 \%$ & $-10.3 \%$ & $1.0 \%$ \\
150 & $1.1 \%$ & $40.0 \%$ & $11.0 \%$ \\
\hline
\end{tabular}

Table 8. Summary of the extension of beef freezing time at zero wind speed.

\begin{tabular}{cccr}
\hline \multirow{2}{*}{ DC magnetic field intensity /G } & \multicolumn{3}{c}{ The time extension of the experimental group compared to the control group/\% } \\
\cline { 2 - 4 } & $0 \sim-5{ }^{\circ} \mathrm{C}$ & $-5{ }^{\circ} \mathrm{C} \sim-18{ }^{\circ} \mathrm{C}$ & $-7.1 \%$ \\
\hline 40 & $-11.0 \%$ & $0.0 \%$ & $-10.3 \%$ \\
50 & $-14.6 \%$ & $2.9 \%$ & $-10.7 \%$ \\
65 & $2.4 \%$ & $48.8 \%$ & $2.5 \%$ \\
90 & $13.3 \%$ & $51.3 \%$ & $23.1 \%$ \\
100 & $22.5 \%$ & $30.5 \%$ \\
\hline
\end{tabular}

the time in the supercooled state. Under the action of the magnetic field strength of $50 \mathrm{G}$ and $150 \mathrm{G}$, the magnetic field reduces the deionization. The degree of supercooling of the water shortens the time of the supercooling state, and under the magnetic field strength of $150 \mathrm{G}$, the reduction of the time of the supercooling state even reaches $188.17 \%$. The magnetic field strength of $50 \mathrm{G}$ has little effect on the effect of saline. Both the $100 \mathrm{G}$ and $150 \mathrm{G}$ magnetic field strengths reduce the minimum non-crystallization temperature of the normal saline, increase the degree of supercooling, and prolong the time in the supercooled state. The $150 \mathrm{G}$ magnetic field strength has a better effect on the normal saline.

Only a certain strength of the magnetic field will have a positive effect on the freezing process of the aqueous solution, and generally speaking, the effect of the magnetic field on the normal saline is better than that of deionized water.

Comparing the data in Table 7 and Table 8, the following conclusions are drawn through the comparison of experimental data:
Magnetic field strength is an important factor affecting the effect of the magnetic field on the freezing process. Magnetic fields of different strengths have different effects on the phase change and freezing stages of the freezing process. Effect. Comparing experimental data, it is found that the magnetic field can not only promote the freezing process but also inhibit the freezing process.

At a certain wind speed, when the magnetic field strength is $100 \mathrm{G}$, the magnetic field lengthens the freezing time through the phase change phase and shortens the freezing time through the freezing phase. This shows that the role of the magnetic field at different stages under the same magnetic field strength may be different. The magnetic field strength of $40 \mathrm{G}$ and 50G has an obvious promotion effect on the freezing process of beef, and the promotion effect of 50G magnetic field strength on the freezing process is more obvious under a certain wind speed, mainly because the magnetic field accelerates the freezing process, compared with the control group, the duration of the freezing 
process was shortened by $36.7 \%$. Before the fan was added, the $65 \mathrm{G}$ magnetic field began to weakly inhibit the freezing process of beef. After the fan was added, the magnetic field began to weakly inhibit the intensity and increased to $100 \mathrm{G}$, which shows that the presence of the fan prolongs the intensity of the magnetic field's inhibitory effect on the freezing process. The magnetic field strength of 100G 150G has a significant inhibitory effect on the freezing process of beef. The suppression effect of $100 \mathrm{G}$ magnetic field strength on the freezing process at zero wind speed is more obvious than the suppression effect of $150 \mathrm{G}$ magnetic field strength on the freezing process under a certain wind speed.

\section{Conclusion}

This paper uses a self-made experimental device to compare the freezing process of aqueous solution and beef under different strength DC weak magnetic fields. It is concluded that the DC weak magnetic field has a certain influence on the freezing process of deionized water, normal saline, and beef. And the conclusions are as follows:

(1) Within the intensity range of this experiment, different magnetic field strengths have different effects on deionized water and normal saline;

(2) Only a certain strength of the magnetic field will have a positive effect on the freezing process of the aqueous solution, and generally speaking, the effect of the magnetic field on the normal saline is better than that of deionized water;

(3) The magnetic field can not only promote the freezing process of beef, but also inhibit the freezing process, and the effect of the magnetic field at different stages under the same magnetic field strength may also be different. The magnetic field strength of $40 \mathrm{G}$ and $50 \mathrm{G}$ can obviously promote the freezing process of beef, while the magnetic field strength of $100 \mathrm{G} \sim 150 \mathrm{G}$ has a significant inhibitory effect on the freezing process of beef;

(4) Whether the fan is added affects the strength of the magnetic field to inhibit the freezing process of beef. The convective heat exchange caused by the fan strengthens the promotion of the magnetic field on the freezing process, delays the strength of the magnetic field's inhibitory effect, and weakens the magnetic field's inhibitory effect on the freezing process.

\section{Funding}

The article was funded by the Natural Science Foundation of Shandong Province, China (ZR2019MEE030).

\section{References}

Aleksandrov, V. D., Barannikov, A. A., \& Dobritsa, N. V. (2000). Effect of magnetic field on the supercooling of water drops. Inorganic Materials, 36(9), 895-898. http://dx.doi.org/10.1007/BF02758700.

Chang, K. T., \& Weng, C. I. (2006). The effect of an external magnetic field on the structure of liquid water using molecular dynamics simulation. Journal of Applied Physics, 100(4), 043917. http://dx.doi. org/10.1063/1.2335971.

Chang, K. T., \& Weng, C. I. (2008). An investigation into the structure of aqueous $\mathrm{NaCl}$ electrolyte solutions under magnetic fields. Computational Materials Science, 43(4), 1048-1055. http://dx.doi. org/10.1016/j.commatsci.2008.02.020.

Choi, Y. S., Ku, S. K., Jeong, J. Y., Jeon, K. H., \& Kim, Y. B. (2015). Changes in ultrastructure and sensory characteristics on electro-magnetic and air blast freezing of beef during frozen storage. Korean Journal for Food Science of Animal Resources, 35(1), 27-34. http://dx.doi. org/10.5851/kosfa.2015.35.1.27. PMid:26761797.

Chen, Z., Wang, H., \& Huang, Y. (2008). Experiment and device on how magnetic field influencing solution crystal. Journal of Jiangsu University, 29(5), 428-431.

Erikson, U., Kjørsvik, E., Bardal, T., Digre, H., Schei, M., Søreide, T. S., \& Aursand, I. G. (2016). Quality of atlantic cod frozen in cell alive system, air-blast, and cold storage freezers. Journal of Aquatic Food Product Technology, 25(7), 1001-1020. http://dx.doi.org/10.1080/1 0498850.2015.1007542.

Guo, B., Han, H., \& Chai, F. (2011). Influence of magnetic field on microstructural and dynamic properties of sodium, magnesium and calcium ions. Transactions of Nonferrous Metals Society of China, 21, s494-s498. http://dx.doi.org/10.1016/S1003-6326(11)61631-2.

Holysz, L., Szczes, A., \& Chibowski, E. (2007). Effects of a static magnetic field on water and electrolyte solutions. Journal of Colloid and Interface Science, 316(2), 996-1002. http://dx.doi.org/10.1016/j. jcis.2007.08.026. PMid:17897662.

Iwasaka, M., Onishi, M., Kurita, S., \& Owada, N. (2011). Effects of pulsed magnetic fields on the light scattering property of the freezing process of aqueous solutions. Journal of Applied Physics, 109(7), 07E320. http://dx.doi.org/10.1063/1.3556776.

James, C., Reitz, B., \& James, S. J. (2015). The freezing characteristics of garlic bulbs (Allium sativum L.) frozen conventionally or with the assistance of an oscillating weak magnetic field. Food and Bioprocess Technology, 8(3), 702-708. http://dx.doi.org/10.1007/ s11947-014-1438-z.

Kiani, H., \& Sun, D.-W. (2011). Water crystallization and its importance to freezing of foods: a review. Trends in Food Science \& Technology, 22(8), 407-426. http://dx.doi.org/10.1016/j.tifs.2011.04.011.

Kim, Y. B., Woo, S. M., Jeong, J. Y., Ku, S. K., Jeong, J. W., Kum, J. S., \& Kim, E. M. (2013). Temperature changes during freezing and effect of physicochemical properties after thawing on meat by air blast and magnetic resonance quick freezing. Han-gug Chugsan Sigpum Haghoeji, 33(6), 763-771. http://dx.doi.org/10.5851/kosfa.2013.33.6.763.

Li, B., \& Sun, D.-W. (2002). Novel methods for rapid freezing and thawing of foods - a review. Journal of Food Engineering, 54(3), 175-182. http://dx.doi.org/10.1016/S0260-8774(01)00209-6.

Mok, J. H., Choi, W., Park, S. H., Lee, S. H., \& Jun, S. (2015). Emerging pulsed electric field (PEF) and static magnetic field (SMF) combination technology for food freezing. International Journal of Refrigeration, 50, 137-145. http://dx.doi.org/10.1016/j.ijrefrig.2014.10.025.

Otero, L., Pérez-Mateos, M., Rodríguez, A. C., \& Sanz, P. D. (2017). Electromagnetic freezing: Effects of weak oscillating magnetic fields on crab sticks. Journal of Food Engineering, 200, 87-94. http://dx.doi. org/10.1016/j.jfoodeng.2016.12.018.

Pang, X.-F., \& Deng, B. (2008). The changes of macroscopic features and microscopic structures of water under influence of magnetic field. Physica B, Condensed Matter, 403(19-20), 3571-3577. http:// dx.doi.org/10.1016/j.physb.2008.05.032. 
Simon, M. D., Heflinger, L. O., \& Geim, A. K. (2001). Diamagnetically stabilized magnet levitation. American Journal of Physics, 69(6), 702-713. http://dx.doi.org/10.1119/1.1375157.

Suzuki, T., Takeuchi, Y., Masuda, K., Watanabe, M., Shirakashi, R., Fukuda, Y., \& Takai, K. (2009). Experimental investigation of effectiveness of magnetic field on food freezing process. Trans. of the JSRAE, 26, 371-386.

Szcześ, A., Chibowski, E., Hołysz, L., \& Rafalski, P. (2010). Effects of static magnetic field on water at kinetic condition. Chemical Engineering and Processing: Process Intensification, 50(1), 124-127. http://dx.doi.org/10.1016/j.cep.2010.12.005.

Toledo, E. J. L., Ramalho, T. C., \& Magriotis, Z. M. (2008). Influence of magnetic field on physical-chemical properties of the liquid water: Insights from experimental and theoretical models. Journal of Molecular Structure, 888(1-3), 409-415. http://dx.doi.org/10.1016/j.molstruc.2008.01.010.

Ueno, S., \& Iwasaka, M. (1994). Parting of water by magnetic fields. IEEE Transactions on Magnetics, 30(6), 4698-4700. http://dx.doi. org/10.1109/20.334193.
Woo, M. W., \& Mujumdar, A. S. (2010). Effects of Electric and Magnetic Field on Freezing and Possible Relevance in Freeze Drying. Drying Technology, 28(4), 433-443. http://dx.doi.org/10.1080/07373930903202077.

Wowk, B. (2012). Electric and magnetic fields in cryopreservation. Cryobiology, 64(3), 301-303, author reply 304-305. http://dx.doi. org/10.1016/j.cryobiol.2012.02.003. PMid:22330639.

Xanthakis, E., Le-Bail, A., \& Havet, M. (2014). Freezing combined with electrical and magnetic disturbances. In D.-W. Sun (Ed.), Emerging technologies for food processing (pp. 563-579). Cambridge: Academic Press. http://dx.doi.org/10.1016/B978-0-12-4114791.00030-9.

Yamamoto, N., Tamura, S., Matsushita, J., \& Ishimu, K. (2005). Fracture properties and microstructure of chicken breasts frozen by electromagnetic freezing. Journal of Home Economics of Japan, 56, 141-151. http://dx.doi.org/10.11428/jhej1987.56.141.

Zhou, Z., Zhao, H., \& Han, J. (2012). Supercooling and crystallization of water under DC magnetic fields. CIESC Journal, 5(63), 1405-1408. 